\title{
Reducing Rate of Iron Oxide in Molten Slag by Carbon
}

\section{in Molten Iron*}

\author{
By Akira SATO,** Goro ARAGANE,** Fumio HIROSE,** \\ Ryuichi NAKAGAWA** and Shiro YOSHIMATSU**
}

\section{Synopsis}

In the research of a continuous ironmaking process from reduced iron, or pre-reduced iron ore, the reduction rate of iron oxide in molten slag by carbon in molten iron was investigated to know the optimum condition. Mixture consisted of, mainly, $40 \mathrm{~g}$ master slag and $17.1 \mathrm{~g}$ iron oxide, was added onto the molten iron in a graphite crucible, the molten copper in a graphite crucible, or the molten iron in an almina crucible to measure the amount of $\mathrm{CO}$ gas evolved in the range of $1320 \sim 1620^{\circ} \mathrm{C}$. The following results were obtained:

(1) The reduction rate of iron oxide in molten slag by carbon in molten iron, or graphite was proportional to the second power of the iron oxide content in the molten slag except for the starting and the ending periods of the experiment.

(2) The rate contant and the apparent activation energ $y$ of the reduction of iron oxide in molten slag by carbon in molten iron were obtained from the data of the experiment with a graphite crucible-molten iron and a graphite crucible-molten copper.

(3) The maximum rate constant of the reduction of iron oxide in molten slag by carbon in molten iron, or graphite was observed around $\mathrm{CaO} / \mathrm{SiO}_{2}=1.5$ of molten slag.

\section{Introduction}

The melting behavior of directly reduced iron pellets into molten iron is considered to be very significant for the continuous iron and steelmaking process which has been studied at the National Research Institute for Metals since 1974. There is a molten slag on the molten iron inevitably, which is formed from the gangue component in pellets. The molten slag is necessary to stabilize the arc. The iron oxide retained in pellets dissolved into the molten slag on the molten iron as shown in the previous report. ${ }^{1)}$ In order to improve the iron yield in the furnace, it is very important to examine the reduction rate of the iron oxide in the molten slag.

In this report, the reduction rate of iron oxide in the molten slag by carbon in the molten iron was investigated to grasp the optimum reduction condition.

\section{Previous Research}

Many studies have been reported on the reduction of iron oxide in molten slag by solid carbon. ${ }^{2)}$ But as for the reduction of iron oxide in molten slag by the carbon in molten iron, the researches were carried out mainly with the blast furnace slag whose iron oxide content was less than $15 \%$. These are as follows :

Philbrook and Kurkbride ${ }^{3)}$ measured the $\mathrm{FeO}$ content in molten slag of $47 \% \mathrm{CaO}-38 \% \mathrm{SiO}_{2}-15 \% \mathrm{Al}_{2} \mathrm{O}_{3}$ melted in a graphite crucible. The initial content of $\mathrm{FeO}$ in the molten slag was less than $5 \%$. The rate of the slag-metal reaction was $5.8 \times 10^{-4} \mathrm{~g}-\mathrm{FeO} / \mathrm{min}$. $\mathrm{cm}^{2} \cdot(w \mathrm{t} \% \mathrm{FeO})^{2}$ at $1430^{\circ} \mathrm{C}$.

Tarby and Philbrook ${ }^{4)}$ measured the $\mathrm{FeO}$ content in molten slag of $50 \% \mathrm{CaO}-10 \% \mathrm{SiO}_{2}-40 \% \mathrm{Al}_{2} \mathrm{O}_{3}$ and $50 \% \mathrm{CaO}-40 \% \mathrm{SiO}_{2}-10 \% \mathrm{Al}_{2} \mathrm{O}_{3}$ melted in a graphite crucible under a stream of $\mathrm{CO}$ gas. The initial content of $\mathrm{FeO}$ in the molten slag was less than $5 \%$. The reaction rates obtained at 1500 and $1575^{\circ} \mathrm{C}$ were proportional to the $1.5 \mathrm{th} \sim 2$ nd power of the $\mathrm{FeO}$ content in the molten slag during the first period when the $\mathrm{CO}$ gas evolved vigorously, and proportional to the content in the second period when the $\mathrm{CO}$ gas evolved stangnantly.

Sommerville et $a l .{ }^{5)}$ made a dual crucible to avoid using a graphite crucible. The inner and the outer crucibles were composed of alumina and steel, respectively. CO gas evolved was measured by a manometer. The molten slag of $40 \% \mathrm{CaO}-40 \%$ $\mathrm{SiO}_{2}-20 \% \mathrm{Al}_{2} \mathrm{O}_{3}$ containing $2 \sim 3 \% \mathrm{FeO}$ reacted with the molten iron in nitrogen atmosphere. The reaction rate obtained was $2.0 \times 10^{-2} \mathrm{~mol} / \mathrm{min} \cdot \mathrm{cm}^{2} \cdot \mathrm{atm}$ at $1380^{\circ} \mathrm{C}$.

\section{Attempt of the Present Research}

The previous reports show that graphite is the only usable crucible material at present for conducting the experiment on the reaction between the molten iron and molten slag containing iron oxide. ${ }^{6)}$ When a graphite crucible is used, it is required to discriminate the slag-metal reaction from the slag-graphite reaction.

When molten copper is used in stead of molten iron, the reduction of iron oxide in the molten slag by carbon in the molten metal can be excluded because the molten copper has a very low carbon solubility. ${ }^{7)}$

The reaction mechanism proposed so far are those based on the chemical and the electro-chemical reactions..$^{6,8)}$ The chemical reactions at the graphite and the molten iron interfaces are expressed by Eqs. (1) and (2), respectively.

$$
\begin{aligned}
& (\mathrm{FeO})+\mathrm{C}(\mathrm{gr}) \longrightarrow \mathrm{Fe}+\mathrm{CO}(\mathrm{g}) \\
& (\mathrm{FeO})+\underline{\mathrm{C}} \longrightarrow \mathrm{Fe}+\mathrm{CO}(\mathrm{g}) \ldots .
\end{aligned}
$$

The electro-chemical reactions in the case of molten copper in a graphite crucible are exhibited by Eq. (3), (4) and (5), respectively.

$$
\begin{aligned}
& \mathrm{O}^{2-}+\mathrm{C}(\mathrm{gr}) \longrightarrow \mathrm{CO}(\mathrm{g})+2 e \quad . \\
& \mathrm{Fe}^{2+}+2 e \longrightarrow \mathrm{Fe} \text { (on graphite) }
\end{aligned}
$$

* Originally published in Tetsu-to-Hagané, 69 (1983), 384, in Japanese. English version received September 2, 1983. C) 1984 ISIJ ** National Research Institute for Metals, Nakameguro, Meguro-ku, Tokyo 153. 


$$
\mathrm{Fe}^{2+}+2 e \longrightarrow \mathrm{Fe} \text { (on copper) }
$$

The reaction, $\mathrm{FeO}+2 \mathrm{Cu}=\mathrm{Cu}_{2} \mathrm{O}+\mathrm{Fe}$, can be negligible because the concentration of $\mathrm{Cu}_{2} \mathrm{O}$ in the molten copper is below $3 \times 10^{-5} \mathrm{wt} \%$ even at $1620^{\circ} \mathrm{C} .{ }^{9)}$ The iron reduced can dissolve in to the molten copper because they make a solution.

The electro-chemical reactions in the case of molten iron in a graphite crucible are as follows:

$$
\begin{aligned}
& \mathrm{O}^{2-}+\mathrm{C}(\mathrm{gr}) \longrightarrow \mathrm{CO}(\mathrm{g})+2 e \\
& \mathrm{O}^{2-}+\mathrm{G} \longrightarrow \mathrm{CO}(\mathrm{g})+2 e \ldots \ldots \\
& \mathrm{Fe}^{2+}+2 e \longrightarrow \mathrm{Fe} \text { (on graphite) } \\
& \mathrm{Fe}^{2+}+2 e \longrightarrow \mathrm{Fe} \text { (on iron) } \ldots . .
\end{aligned}
$$

It has been confirmed that the slag-metal and -graphite reactions proceed electro-chemically by the fact that the reaction rate is affected by the electric current flowed. The anodic reaction is reported to determine the rate of $\mathrm{SiO}_{2}$ reduction by carbon in the molten iron for up to 20 of the interfacial area ratio of the slag-graphite to the slag-metal. ${ }^{8,10)}$ This ratio is nearly 1.4 at most in the present experiment. The reduction rate of $\mathrm{FeO}$ is greater than that of $\mathrm{SiO}_{2}$. The slag containing $\mathrm{FeO}$ is strongly agitated by the $\mathrm{CO}$ gas evolution. Therefore, the reduction of iron oxide in the molten slag is considered to be determined by the anodic reaction.

The cathodic reaction (5) can be regarded as the same as that of (9), because both the molten copper and iron have electric conductivity. There is, however, no evidence that the anodic reaction (7) has no effect on the anodic one (6) in the case of the molten iron in the graphite crucible. Nevertheless, the anodic reaction (3) in the case of the molten copper in the graphite crucible can be considered the nearly same as that of (6) in the case of the molten iron in the graphite crucible as far as the anodic reaction determines the rate.

It is reported, moreover, that a quantitative rate equation of the electro-chemical reactions can not be obtained right now, though the results can be explained excellently by the electro-chemical reactions. ${ }^{6)}$ Hence, the chemical reactions (1) and (2) must be used in the present report. The rate of the slag-metal reaction can be calculated on the base of the assumption that the rate of the slag-graphite reaction in the case of the molten copper in the graphite crucible is the same as that in the case of the molten iron in the graphite crucible.

The rate of slag-metal reaction was examined using the alumina crucible to whose bottom a graphite block was bonded, because the erosion of this crucible by the molten slag was much less than that of the other crucibles except for a graphite one.

Considering that the composition of the molten slag during the reaction may not be uniform, and that the sampling for the chemical analysis may disturb the reaction, the reaction rate is determined by measuring the amount of $\mathrm{CO}$ gas evolved.

The main experimental condition are as follows: The FeO content in the molten slag is decided to be
$30 \%$ in consideration of steelmaking slags. The weight of the master slag is $40 \mathrm{~g}$ ( $2.7 \%$ of the metal), and the thickness of the molten slag without foramgin is about $1 \mathrm{~cm}$. The experimental temperature is $1520^{\circ} \mathrm{C}$.

\section{Experimental}

A Tammann furnace was used for the reduction experiment under a controlled atmosphere. ${ }^{1)}$ The molten metal was kept at a desired temperature within $\pm 5^{\circ} \mathrm{C}$. The amount of $\mathrm{CO}$ gas evolved was measured with an integrating gas meter. Nitrogen gas was flowed at the rate of $60 l / \mathrm{h}$ in order to measure a small amount of $\mathrm{CO}$ gas evolved, because the measurable range of this meter was $5 \sim 300 l / \mathrm{h}$.

The master slag powder of under $1 \mathrm{~mm}$ diameter was made from $\mathrm{CaO}(95.2 \% \mathrm{CaO}), \mathrm{SiO}_{2}(99.8 \%$ $\mathrm{SiO}_{2}$ ) and $\mathrm{Al}_{2} \mathrm{O}_{3}$ (first grade chemical reagent) in a graphite crucible in an induction furnace. The chemical compositions of the slags having the ratios $\mathrm{CaO} / \mathrm{SiO}_{2}$ of $0.5,1,1.5$ and 2 were as follows:

$24.0 \% \mathrm{CaO}-65.5 \% \mathrm{SiO}_{2}-10.5 \% \mathrm{Al}_{2} \mathrm{O}_{3}$

$44.2 \% \mathrm{CaO}-45.0 \% \mathrm{SiO}_{2}-10.8 \% \mathrm{Al}_{2} \mathrm{O}_{3}$

$53.2 \% \mathrm{CaO}-36.1 \% \mathrm{SiO}_{2}-10.7 \% \mathrm{Al}_{2} \mathrm{O}_{3}$

$57.5 \% \mathrm{CaO}-31.8 \% \mathrm{SiO}_{2}-10.7 \% \mathrm{Al}_{2} \mathrm{O}_{3}$.

$\mathrm{FeO}(93.8 \% \mathrm{FeO})$ powder was made from $\mathrm{Fe}_{2} \mathrm{O}_{2}$ one equivalent to the first grade chemical reagent.

The molten metal was made from electrolytic iron and electrode graphite, or cathode copper.

Figure 1 illustrates an example of the crucible arrangement and the addition method of slag-iron oxide powder mixture. The inner diameter and the depth of the crucible were $5.5 \mathrm{~cm}$ and $19 \mathrm{~cm}$, respectively.

The experimental procedure was described as follows: Metal weighing about $1.5 \mathrm{~kg}$ was melted under nitrogen atmosphere and held at the experimental temperature for $30 \mathrm{~min}$. The surface of the molten metal was cleaned before and after the addition of a small amount of $\mathrm{Fe}_{2} \mathrm{O}_{3}$. The samples for the chemical analysis of $\mathrm{Si}$ and $\mathrm{C}$ were taken to con-

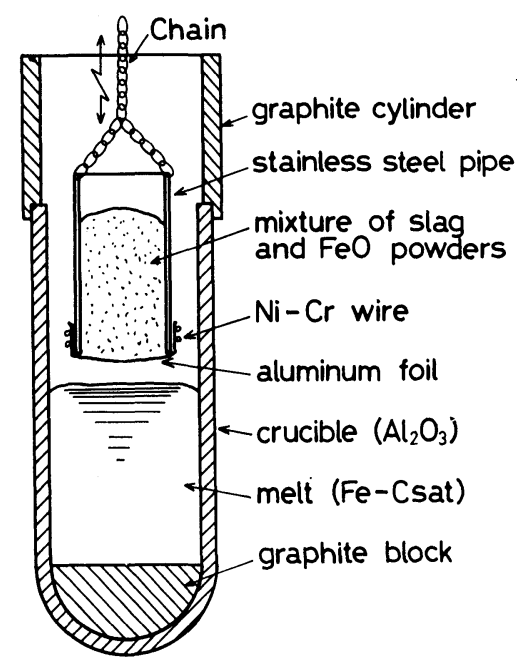

Fig. 1. Shematic diagram of the crucible arrangement and the addition method of the master slag and iron oxide powder mixture. 
firm the initial experimental condition. The container of slag-iron oxide powder mixture was set in the apparatus. Then, the container was lowered at the position about $5 \mathrm{~mm}$ high above the molten metal surface, after the nitrogen gas flow rate was measured for $2 \mathrm{~min}$. The aluminum foil which covered the bottom of the container was melted and the mixture fell down onto the molten metal surface. From that moment, the flow rate of gas was recorded every minute for $30 \mathrm{~min}$. After the end of each experimental run, the molten slag was taken out by a nickel bar, and the contents of $\mathrm{FeO}, \mathrm{Al}_{2} \mathrm{O}_{3}, \mathrm{SiO}_{2}$ and $\mathrm{CaO}$ were analyzed. A metal sample for $\mathrm{Si}$ analysis was taken after the removal of the molten slag. The reproducibility was confirmed by the results of the duplicated runs in the same experimental condition.

\section{Results}

The master slag-iron oxide mixture which was added onto the molten metal surface was melted within 1 1.5 min in almost all the experimental conditions. In the case of the experimental temperature of $1320^{\circ} \mathrm{C}$, the master slag of $\mathrm{CaO} / \mathrm{SiO}_{2}=2$, or the master slag weight of $80 \mathrm{~g}$, the time for melting of the mixture was within $3 \mathrm{~min}$. The molten slag foamed in the present experiment as a result of the $\mathrm{CO}$ gas evolution. The foaming phenomenon was observed remarkably in the case of the alumina crucible.

The aluminum foil which covers the bottom of the container is thin enough, and the weight of $\mathrm{FeO}$ required to oxidize the foil is $0.1 \mathrm{~g}$ at most.

The $\mathrm{Al}_{2} \mathrm{O}_{3}$ contents in the molten slag after $30 \mathrm{~min}$ experimental runs in the case of the alumina crucible at $1320,1420,1520$ and $1620^{\circ} \mathrm{C}$ were about 10 , 20,30 and $40 \%$, respectively.

No significant increase of the silicon content in the molten iron was observed when the $\mathrm{CaO} / \mathrm{SiO}_{2}$ of the molten slag was 1.5 and 1 . The $\mathrm{Si}$ content in the molten iron increased by about $0.08 \%$ even when the molten slag of $\mathrm{CaO} / \mathrm{SiO}_{2}=0.5$ was reduced at $1620^{\circ} \mathrm{C}$ in a graphite crucible. This indicates that about $10 \%$ of $\mathrm{SiO}_{2}$ in the $40 \mathrm{~g}$ molten slag is reduced. Therefore, the reduction of $\mathrm{SiO}_{2}$ in the molten slag is considered to be negligible.

The ratio of the amount of $\mathrm{CO}$ gas measured to that calculated from the $\mathrm{FeO}$ analysis of the molten slag after $30 \mathrm{~min}$ experimental run was about 1.2, while it was less than unity in the case of the molten slag of $\mathrm{CaO} / \mathrm{SiO}_{2}=0.5$ at lower temperature. ${ }^{11)}$ The $\mathrm{FeO}$ content along with the experimental time was calculated according to the initial $\mathrm{FeO}$ content and the amount of $\mathrm{CO}$ gas evolved.

Figure 2 indicates the effects of the crucible materials, the kinds of molten metal and the slag weights on the relations between the amount of $\mathrm{FeO}$ reduced and the times. The experimental conditions used were $1520^{\circ} \mathrm{C}$ of the temperature, unity of $\mathrm{CaO} / \mathrm{SiO}_{2}$ in the molten slag and $30 \%$ of the initial $\mathrm{FeO}$ content. When the weight of the master slag was $80 \mathrm{~g}$, no significant difference was observed in the relation with the kinds of the molten metal in graphite crucible.
On the other hand, the reduced amount of $\mathrm{FeO}$ was greater on the molten iron than that on the molten copper in the cases of the master slag being 40 and $20 \mathrm{~g}$.

The difference in the crucible material had hardly the effect on the relations when the weight of the master slag was $10 \mathrm{~g}$, but the $\mathrm{FeO}$ reduced amount was more in a graphite crucible than in an alumina one when the weights of the master slag were 80,40 and $20 \mathrm{~g}$.

Figure 3 denotes the effects of the crucible material and the initial iron oxide content on the relations between the iron oxide concentration in the molten slag and the time. The temperature, the ratio $\mathrm{CaO} /$ $\mathrm{SiO}_{2}$ and the weight of the master slag used in the experimental runs were $1520^{\circ} \mathrm{C}$, unity and $40 \mathrm{~g}$,

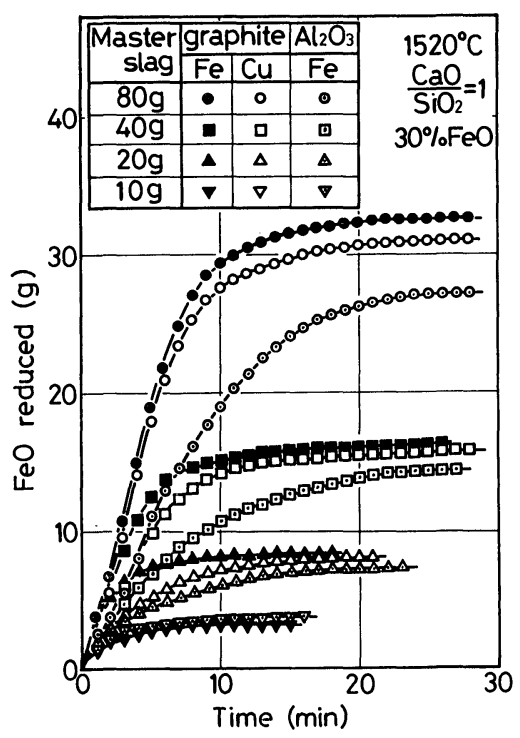

Fig. 2. Effects of the crucible material, the metal melt and the slag weight on the relations between the amount of $\mathrm{FeO}$ reduce and the time.

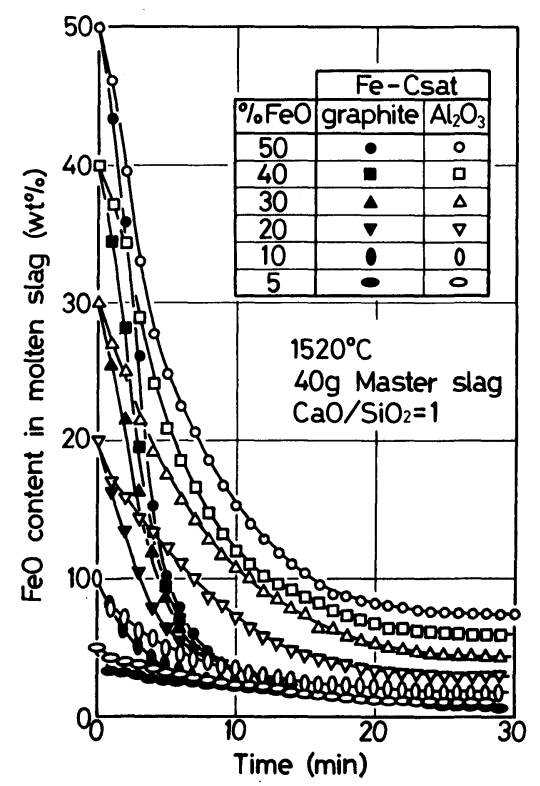

Fig. 3. Effects of the crucible material and the initial iron oxide content on the relations between the iron oxide content in the molten slag and the time. 
respectively. The kind of molten metal had barely the effect on the relations. On the other hand, the iron oxide content in the molten slag was much higher in an alumina crucible at the same experimental time than that in a graphite one. The final iron oxide content in the molten slag in an alumina crucible increased with increasing the initial iron oxide content.

Figure 4 points out the effects of the crucible material and the molten metal (a), and the $\mathrm{CaO} / \mathrm{SiO}_{2}$ of the molten slag (b) on the relations between the $\mathrm{FeO}$ content in the molten slag after the $30 \mathrm{~min}$ experimental runs and the temperature. The $\mathrm{FeO}$ content in the molten slag was lowest with the molten iron in a graphite crucible, and highest with the molten iron in an alumina one. This value was lowest with the molten slag of $\mathrm{CaO} / \mathrm{SiO}_{2}=1.5$, and highest with that of $\mathrm{CaO} / \mathrm{SiO}_{2}=0.5$. The difference of this value between molten slags of $\mathrm{CaO} / \mathrm{SiO}_{2}=1.5$ and 0.5 increased with decreasing temperature. This value for the molten slag of $\mathrm{CaO} / \mathrm{SiO}_{2}=1$ was slightly higher than that of $\mathrm{CaO} / \mathrm{SiO}_{2}=1.5$. Moreover, this value was very high at $1320^{\circ} \mathrm{C}$ while it was low at
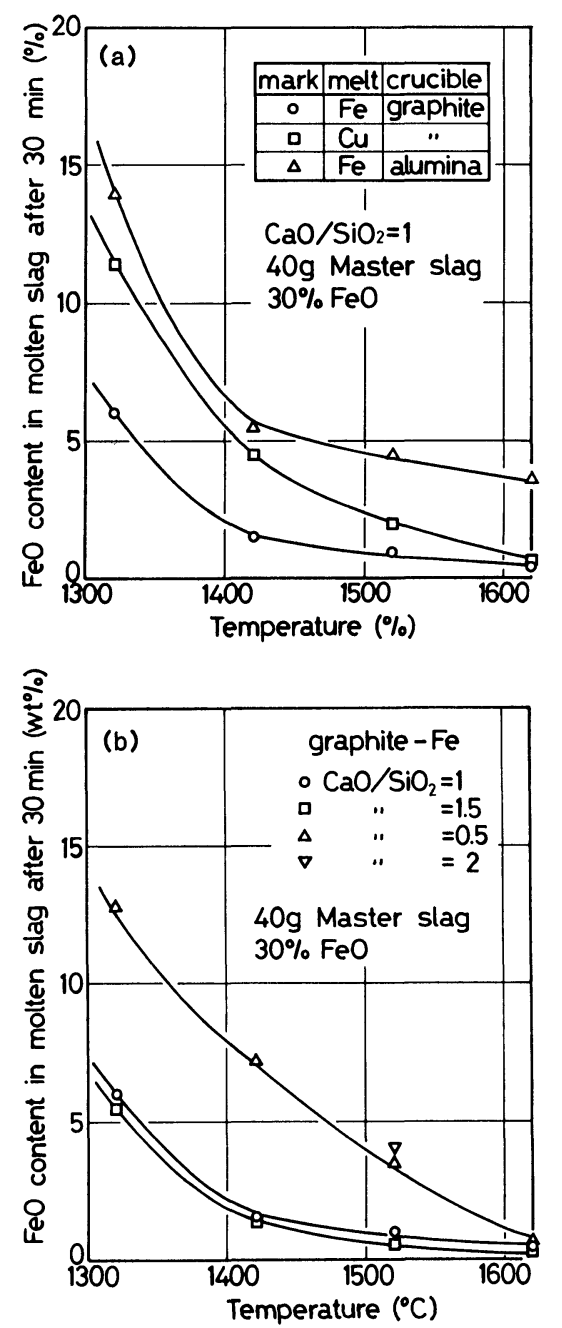

Fig. 4. Effects of the crucible material and the metal melt (a) and the $\mathrm{CaO} / \mathrm{SiO}_{2}$ of the molten slag (b) on the relation between the $\mathrm{FeO}$ content in the molten slag after the $30 \mathrm{~min}$ experimental runs and the temperature. $1620^{\circ} \mathrm{C}$.

\section{Discussion}

The result shown in Fig. 2 can be explained well by the difference in the interfacial area of slag-metal and slag-graphite. When the weight of the master slag is $80 \mathrm{~g}$, the slag-graphite reaction is dominant between the molten slag and the crucible wall. Therefore, the molten metal has small effect on the reduction rate. On the other hand, when the weight of the master slag is $10 \mathrm{~g}$, the slag-metal reaction is dominant between the molten slag and iron. Accordingly, the crucible material has small effect on the reduction rate.

The effects of the temperature, the crucible material, the molten metal and the $\mathrm{CaO} / \mathrm{SiO}$ of the master slag on the $\mathrm{FeO}$ content in the molten slag after the 30 min experimental runs can be explained by the viscosity of the molten slag, ${ }^{12)}$ the area of the reaction interface and the activity of iron oxide in the molten slag. ${ }^{13)}$ For the progress of the reaction of iron oxide in the molten slag, the low viscosity, the large area and the high activity are desirable. Therefore, a high temperature, a graphite crucible, molten iron and the molten slag of $\mathrm{CaO} / \mathrm{SiO}_{2}=1.5$ are favorable to reduce the $\mathrm{FeO}$ content in the molten slag. The reason why the $\mathrm{FeO}$ content in the molten slag after the $30 \mathrm{~min}$ experimental runs increased with increasing the initial $\mathrm{FeO}$ content in an alumina crucible can be attributed to the adhesion of the molten slag to the alumina crucible wall.

The reduction rate is calculated by Eq. (10) proposed by Philbrook and Kurkbride. ${ }^{3)}$ This equation is valid when the slag is mixed completely.

$$
\frac{-d W_{\mathrm{FeO}}}{d t}=\frac{S}{100} \cdot \frac{-d C_{\mathrm{FeO}}}{d t}=k \cdot A \cdot\left(C_{\mathrm{Fe} e \mathrm{O}}\right)^{\alpha} \cdot\left(C_{\mathrm{O}}\right)^{\beta}
$$

where, $-d W_{\mathrm{FeO}} / d t$ : the weight of $\mathrm{FeO}$ reduced in $1 \mathrm{~min}(\mathrm{~g} / \mathrm{min})$

$S:$ the weight of molten slag (g)

$C_{\mathrm{FoO}}$ : the $\mathrm{FeO}$ content in molten slag $(\mathrm{wt} \%)$

$C_{\mathrm{C}}:$ the activity of carbon in molten iron (Raoult) or the purity of graphite

$A$ : the area of the reaction interface $\left(\mathrm{cm}^{2}\right)$

$k$ : the apparent rate constant of reaction $\left[\mathrm{g}-\mathrm{FeO} / \mathrm{min} \cdot \mathrm{cm}^{2} \cdot(\mathrm{wt} \%\right.$ $\left.\mathrm{FeO})^{\alpha} \cdot\left(C_{\mathrm{C}}\right)^{\beta}\right]$.

$C_{\mathrm{C}}$ can be regarded as unity, because the carbon saturated molten iron or the pure graphite was used in the present experiment. Philbrook and Kurkbride assumed that $S$ was constant because the initial $\mathrm{FeO}$ content in the molten slag was less than $5 \%$. However, $S$ changes with the time in this experiment because the initial $\mathrm{FeO}$ content in the molten slag is mainly $30 \%$. In the following suffixes 1 and 2 denote the reaction of slag-metal and slag-graphite, respectively. 
In the case of the molten iron in an alumina crucible, the following equation can be used under the assumption that the weight increase of alumina from the crucible wall can be negligible.

$$
\begin{aligned}
& {\left[\log \left(-\frac{d C_{\mathrm{FeO}}}{d t}\right)_{1}-\log \left(\frac{A_{1}}{S}\right)\right]} \\
& \quad=\alpha_{1} \log C_{\mathrm{FeO}}+\log k_{1}+2 \ldots
\end{aligned}
$$

The increasing rate of alumina in the molten slag from the crucible wall is unknown. However, assumed that the alumina content in the molten slag increases with the time up to the value obtained by the analysis, the weight change of the molten slag can be estimated very small. In this case Eq. (12) can be used.

$$
\log \left(-\frac{d C_{\mathrm{FeO}}}{d t}\right)_{1}=\alpha_{1} \log C_{\mathrm{FeO}}+\log k_{1}+\log \left(\frac{A_{1}}{S}\right)+2
$$

Moreover, the result calculated through Eq. (12) where $S$ was assumed constant did not differ from that by Eq. (11) greatly. Therefore, Eq. (12) is used in the case of molten iron in an alumina crucible.

It is very difficult to estimate the area of the reaction interface between the molten slag and the wall of the graphite crucible because of the foaming of the molten slag. $A_{2} / S$ is determined by the diameter of the crucible and the density of the molten slag, and $S$ can be eliminated. However, the density of the molten slag changes with the foaming and can not be estimated. Therefore, the value of $2.5 \mathrm{~g} / \mathrm{cm}^{3}$ is used for the calculation. ${ }^{12)}$ The effect of the $\mathrm{FeO}$ content in the molten slag on the density is also negligible, and Eq. (13) is obtained in the case of molten copper in a graphite crucible.

$$
\log \left(-\frac{d C_{\mathrm{FeO}}}{d t}\right)_{2}=\alpha_{2} \log C_{\mathrm{FeO}}+\log k_{2}+\log \left(\frac{A_{2}}{S}\right)+2
$$

Equation (14) is obtained when the reactions of slag-metal and slag-graphite are not discriminated in the case of molten iron in a graphite crucible.

$$
\begin{aligned}
& {\left[\log \left(-\frac{d C_{\mathrm{FeO}}}{d t}\right)-\log \left(\frac{A_{1}+A_{2}}{S}\right)\right]} \\
& \quad=\alpha \log C_{\mathrm{FeO}}+\log k+2 \ldots \ldots \ldots \ldots \ldots
\end{aligned}
$$

Equation (15) is obtained when the slag-metal reaction can be distinguished from the slag-graphite reaction in the case of molten iron in a graphite crucible. This is based on the assumption of the complete mixing of the slag.

$$
\begin{aligned}
& \left(\left[-\frac{d C_{\mathrm{FeO}}}{d t}\right)_{1}+\left(-\frac{d C_{\mathrm{FeO}}}{d t}\right)_{2}\right] \\
& \quad=\frac{100}{S} \cdot k_{1} A_{1} \cdot\left(C_{\mathrm{FeO}}\right)^{\alpha_{1}}+\frac{100}{S} \cdot k_{2} A_{2} \cdot\left(C_{\mathrm{FeO}}\right)^{\alpha_{2}}
\end{aligned}
$$

Figure 5 shows the effect of the slag weight on the rate constant at $1520^{\circ} \mathrm{C}$. The $\mathrm{CaO} / \mathrm{SiO}_{2}$ and the $\mathrm{FeO}$ content in the slag were unity and $30 \%$, respec-

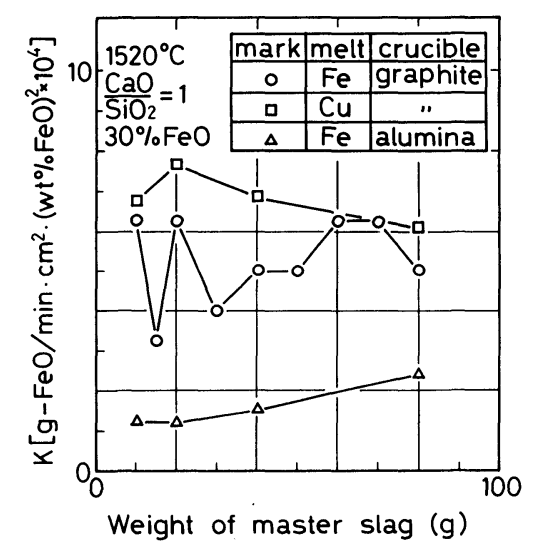

Fig. 5. Effect of the slag weight on the rate constant.

tively. The rate constants in the case of a graphite crucible are nearly constant. The change in the rate constant in the case of the smaller amount of the slag is considered to be great because of the following reasons: The fluctuation of the area due to the slag foaming is large. The rate of the reduction of $\mathrm{FeO}$ in the molten slag is affected by the formation and the runaway of CO gas bubbles. ${ }^{3}$ ) The reason why the rate constant in the case of an alumina crucible is low and appears to have increased slightly with increasing the amount of the slag should be due to the dissolution of alumina from the crucible wall and the adhesion of the molten slag to the crucible wall. This figure indicates that the molten copper has little effect on the reaction rate. In the case of molten copper in a graphite crucible, the rate constants are overestimated because the increase in the interfacial area caused by the slag foaming is neglected.

When the rate of slag-graphite reaction can be obtained by the experiment with molten copper in a graphite crucible, Eq. (11) can be used to calculated the rate of the slag-metal reaction in the case of molten iron in a graphite crucible.

Figures 6, 7, 8 and 9 show the results calculated by Eqs. (12), (13), (14) and (11), respectively. In the most periods except for the beginning and the ending ones of the experiment, the reduction rate of iron oxide in the molten slag is proportional to nearly the second power of the concentration of iron oxide in the molten slag regardless of the kinds of the crucible material and the molten metal, the $\mathrm{CaO} / \mathrm{SiO}_{2}$ of the master slag, the experimental temperature, the weight of the molten slag, and the initial iron oxide concentration in the molten slag. In the beginning period, the deviation from the above mentioned relation is considered to be due to the time required for melting of the mixture of the master slag and iron oxide. In the ending period, the deviation is considered to be due to the low concentration of iron oxide in the molten slag. When the concentration of iron oxide in the molten slag is low, the reduction rate decreases with decreasing the stirring effect of $\mathrm{CO}$ gas which evolved slowly.4) In this range of the iron oxide concentration in the molten slag, it is necessary to use a new apparatus to measure more 


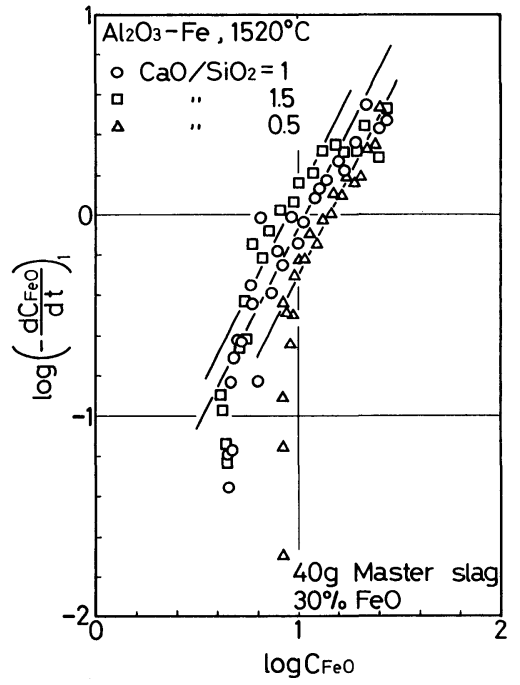

Fig. 6. Relations between $\log \left(-d C_{\mathrm{FeO}} / d t\right)_{1}$ and $\log C_{\mathrm{FeO}}$ based on Eq. (12).

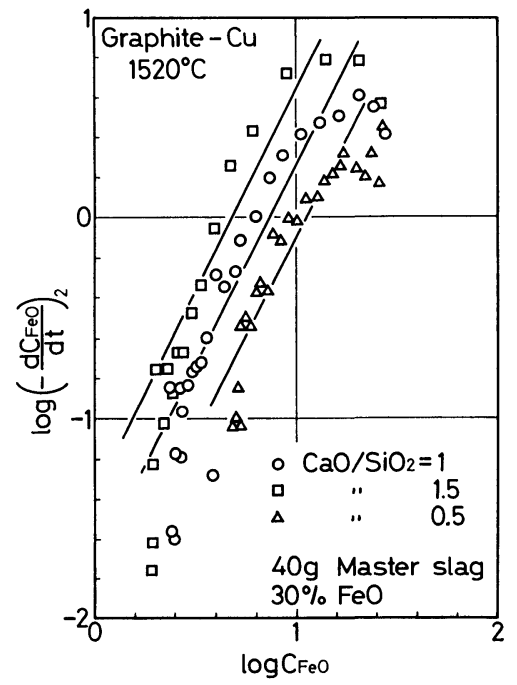

Fig. 7. Relations between $\log \left(-d C_{\mathrm{FeO}} / d t\right)_{2}$ and $\log C_{\mathrm{FeO}}$ based on Eq. (13).

precisely the small amount of $\mathrm{CO}$ gas evolved than that used in this experiment. Therefore, this range is neglected in the present report.

The experimental result that the reduction rate is proportional to the second power of the iron oxide concentration in the molten slag coincided with that obtained by philbrook and Kurkbride. ${ }^{3)}$ It is considered to be due to the acceleration of the reaction by the stirring effect of the $\mathrm{CO}$ gas evolved as proposed by Wagner. ${ }^{14}$

The reaction rate of slag-graphite looks greater than that estimated by the second power relation in the range of $5 \sim 10 \% \mathrm{FeO}$ in the molten slag as shown in Fig. 6. This can be explained by the increase in the reaction area as a result of the severe foaming of the molten slag which has been observed from the window.

Figure 10 to 12 show the relation between the logarithm of the rate constant of the reaction and the reciprocal of the temperature on the assumption that all the proportional constants in Eqs. (12), (13) and

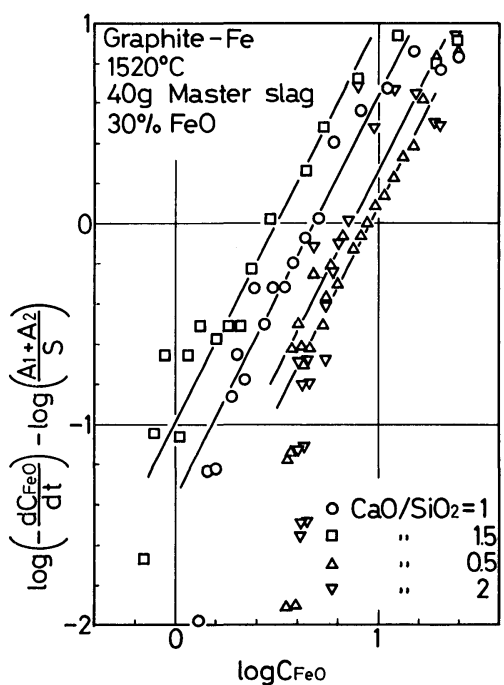

Fig. 8. Relations between $\left[\log \left(-d C_{\mathrm{FeO}} / d t\right)-\log \left(A_{1} / S+\right.\right.$ $\left.\left.A_{2} / S\right)\right]$ and $\log C_{\mathrm{FeO}}$ based on Eq. (14).

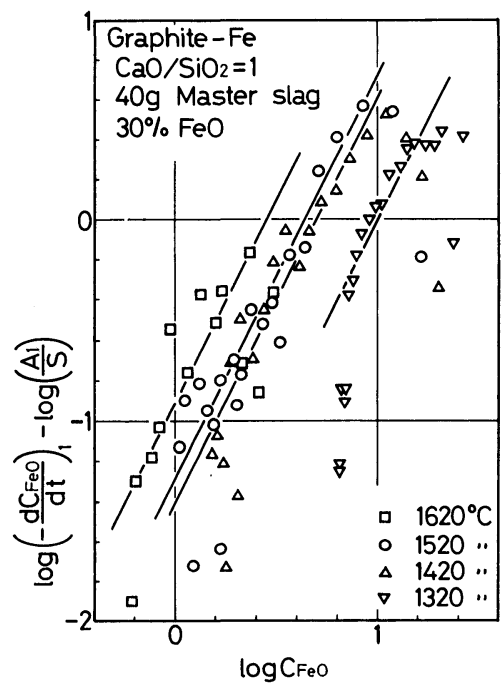

Fig. 9. Relations between $\left[\log \left(-d C_{\mathrm{FeO}} / d t\right)_{1}-\log \left(A_{1} / S\right)\right]$ and $\log C_{\mathrm{FeO}}$ based on Eq. (11).

(11) are 2. The straight relation can be obtained for each $\mathrm{CaO} / \mathrm{SiO}_{2}$ of the master slag. The apparent activation energies of the slag-metal reaction in an alumina crucible are 63,39 and $46 \mathrm{kcal} / \mathrm{mol}$ for the slags of $\mathrm{CaO} / \mathrm{SiO}_{2}$ of $0.5,1$ and 1.5 , respectively. Those of the slag-graphite reaction in a graphite crucible are 82,63 and $57 \mathrm{kcal} / \mathrm{mol}$ for the slags of $\mathrm{CaO} / \mathrm{SiO}_{2}$ of $0.5,1$ and 1.5 , respectively. Those of the slag-metal reaction in a graphite crucible are 39, 47 and $59 \mathrm{kcal} / \mathrm{mol}$ for the slags of $\mathrm{CaO} / \mathrm{SiO}_{2}$ of 0.5 , 1 and 1.5, respectively. The apparent activation energies obtained in the present work are nearly the same as those reported up to now ${ }^{2,4,11,15,16)}$ except for that of the slag-graphite in the case of $\mathrm{CaO} / \mathrm{SiO}_{2}=$ 0.5. The very great temperature dependence of the reaction for the slag of $\mathrm{CaO} / \mathrm{SiO}_{2}=0.5$ is considered to be due to the very high viscosity of the slag at the low temperature. ${ }^{10)}$

The activation energy of $90 \sim 130 \mathrm{kcal} / \mathrm{mol}$ is obtained for the reduction of $\mathrm{SiO}_{2}$ in the slag by carbon in the iron in a graphite crucible. ${ }^{10)}$ The rate of the 


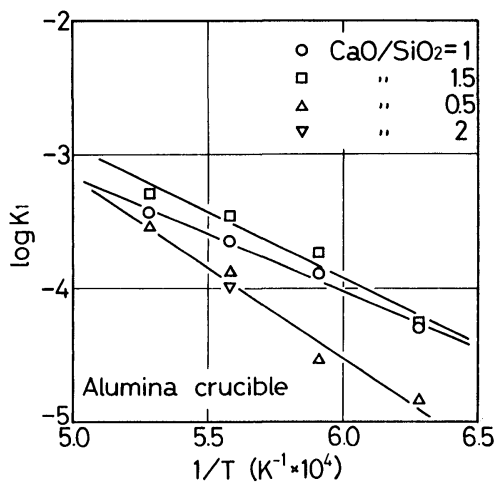

Fig. 10. $\log k_{1}$ and $1 / T$.

$k_{1}$ is calculated by Eq. (12) on the assumption of $\alpha_{1}=2$.

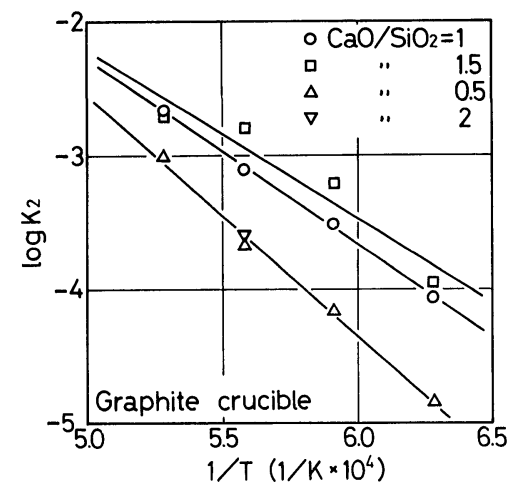

Fig. 11. $\log k_{2}$ and $1 / T$.

$k_{2}$ is calculated by Eq. (13) on the assumption of $\alpha_{2}=2$.

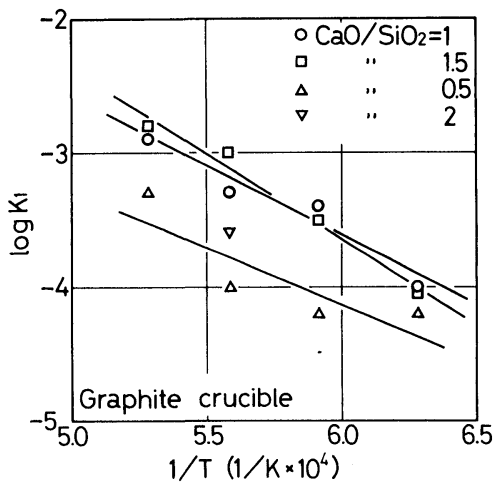

Fig. 12. $\log k_{1}$ and $1 / T$.

$k_{1}$ is calculated by Eq. (11) on the assumption of $\alpha_{1}=2$.

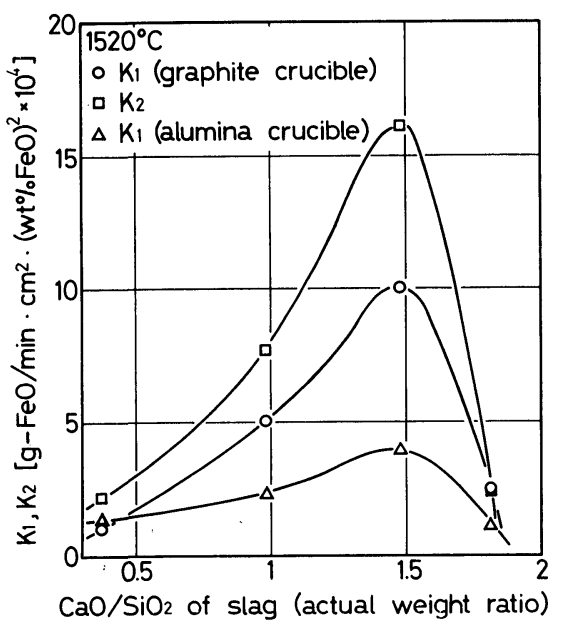

Fig. 13. Effect of the $\mathrm{CaO} / \mathrm{SiO}_{2}$ of the molten slag on the rate constant.

reaction is determined by the interfacial reaction, and the activation energy obtained is explained from the break of the bond between silicon and oxygen. On the other hand, the activation energy obtained in the present experiment is $40 \sim 80 \mathrm{kcal} / \mathrm{mol}$. The rate of the reaction is considered to be mainly determined by the interfacial reaction, though the activation energy can be explained from the reduction of $\mathrm{FeO}$ and the oxygen diffusivity in the slag because the diffusion plays the more important role with increasing the reaction rate.

Figure 13 demonstrates the effect of $\mathrm{CaO} / \mathrm{SiO}_{2}$ in the molten slag on the rate constant of the slag-metal and slag-graphite reactions at $1520^{\circ} \mathrm{C}$. The rate constant is the maximum around 1.5 of $\mathrm{CaO} / \mathrm{SiO}_{2}$. The rate constant of the slag-metal reaction in a graphite crucible is greater than that in an alumina crucible. The activity coefficient of iron oxide in the molten slag is greatest at 2 of the $\mathrm{CaO} / \mathrm{SiO}_{2}$, estimated from the diagram at $1600^{\circ} \mathrm{C} .0^{13)}$ Therefore, it increases with increasing the $\mathrm{CaO} / \mathrm{SiO}_{2}$ in the range of this report. On the other hand, the viscosity of molten slag is the minimum around 1.2 of $\mathrm{CaO} / \mathrm{SiO}_{2} \cdot{ }^{12)}$ Accordingly, the maximum rate constant around 1.5 of $\mathrm{CaO} / \mathrm{SiO}_{2}$ can be considered by the effect of both the activity coefficient of iron oxide in the molten slag and the viscosity of the molten slag. The low rate constant in an alumina crucible is considered to be due to the increasing viscosity and the decreasing activity coefficient of iron oxide in the molten slag because of the increase in alumina in the molten slag from the crucible wall.

\section{Conclusion}

In the research on a continuous ironmaking process from direct reduction iron, or pre-reduced iron ore, the reducing rate of iron oxide in molten slag by carbon in molten iron was investigated to grasp the optimum reducing condition. Mixtures consisted of, mainly, $40 \mathrm{~g}$ master slag $(2.7 \%$ of molten metal) and $17.1 \mathrm{~g}$ iron oxide $(30 \% \mathrm{FeO}$ in molten slag) were added onto molten iron in a graphite crucible, molten copper in a graphite crucible, or molten iron in an alumina crucible to measure the amount of the $\mathrm{CO}$ gas evolved in the range of $1320 \sim 1620^{\circ} \mathrm{C}$. The following results were obtained:

(1) The reduction rate of iron oxide in the molten slag by carbon in the molten iron and graphite was proportional to the second power of the iron oxide concentration in the molten slag in the period except for the starting and ending ones of the experiment.

(2) The apparent activation energies of the slaggraphite reaction obtained by the experiment with molten copper in a graphite crucible were 82,57 and $63 \mathrm{kcal} / \mathrm{mol}$ for the slags of $\mathrm{CaO} / \mathrm{SiO}_{2}$ of $0.5,1$ and 1.5 , respectively.

(3) The apparent activation energies of the slagmetal reaction obtained by the experiment with molten iron in a graphite crucible using the data of the slag-graphite reaction obtained by the experiment with molten copper in a graphite crucible were 39,47 and $59 \mathrm{kcal} / \mathrm{mol}$ for the slags of $\mathrm{CaO} / \mathrm{SiO}_{2}$ of $0,5,1$ and 1,5 , respectively.

(4) The rate constant of the slag-metal reaction in an alumina crucible was smaller than that in a graphite crucible as a result of the alumina dissolution into the molten slag from the crucible wall.

(5) The maximum rate constant of the reduction of iron oxide in the molten slag by carbon in the molten iron or graphite was observed around 1.5 of the $\mathrm{CaO} / \mathrm{SiO}_{2}$ of the molten slag. 


\section{REFERENCES}

1) A. Sato, R. Nakagawa, S. Yoshimatsu, A. Fukuzawa and T. Ozaki: Trans. ISIJ, 20 (1980), 33.

2) For example; B. B. Kondakov and D. I. Riydjonkov: Izv. VUZov, Cher. Met., (1963), 17.

M. Sugata, T. Sugiyama and S. Kondo: Tetsu-to-Hagané, 58 (1972), 1363.

3) W. O. Philbrook and L. D. Kurkbride: J. Metals, 8 (1956), 351.

4) S. K. Tarby and W. O. Philbrook: Trans. AIME, 239 (1967), 1005.

5) I. D. Sommerville, P. Grieveson and J. Taylor: Ironmaking Steelmaking, 7 (1980), 25.

6) Y. Kawai and K. Mori: Tetsu-to-Hagané, 58 (1972), 932.

7) Metals Handbook, VIII, ed. by ASM, ASM, Metals Park, (1973).
8) Iron and Steel Handbook, I: Foundamental Theory of Iron and Steel, ed. by ISIJ, Maruzen, Tokyo, (1981), 77-143.

9) E. T. Turkdogan: Physical Chemicstry of High Temperature Technology, Academic Press, New York, (1980).

10) M. Ashizuka, M. Tokuda and M. Otani: Tetsu-to-Hagané, 54 (1968), 1437.

11) A. Sato, R. Nakagawa, S. Yoshimatsu, A. Fukuzawa and T. Ozaki: Trans. ISIJ, 21 (1981), 879.

12) Spe. Rep. No. 12, A Handbook on Properties of Liquid Iron and Slag, ed. by ISIJ, ISIJ, Tokyo, (1972).

13) J. F. Elliott: J. Metals, 7 (1955), 485.

14) C. Wagner: Physical Chemistry of Steelmaking, ed. by J. F. Elliott, John Wiley and Sons, New York, (1958), 237.

15) G. W. Lloyd, D. R. Yong and L. A. Baker: Ironmaking Steelmaking, 2 (1975), 49.

16) D. R. Sain and G. R. Belton: Met. Trans., 7B (1976), 235. 